\title{
Prevalence and Pattern of Sleep Disturbances among Mood Disorder Inpatients
}

\author{
Gayathiri Mohankumar ${ }^{1 *}$, Dr Pradeep Palaniappan ${ }^{2}$
}

\section{ABSTRACT}

Sleep disorders are highly prevalent in psychiatric illnesses such as major depressive disorder, bipolar disorder. Early identification of sleep disturbances in these disorders would help us prevent the worsening of the illness further. We conducted a study regarding the sleep disturbances among patients admitted with a diagnosis of mood disorder using a questionnaire Pittsburgh Sleep Quality Index. The details of the patients were collected by means of a semi structured proforma. We analysed the results statistically using SPSS software version 19.The results revealed an equivocal distribution of sleep disturbances in mood disorder. Sleep disturbances prevail in spite of being on medications. Thus our study results emphasize that equally poor sleep quality exists among all mood disorder inpatients irrespective of their diagnostic status. Hence treating the sleep disturbances in these patients will enhance their quality of life.

Keywords: Prevalence, Pattern, Sleep Disturbances, Mood Disorder

Depression is the most common and serious mental illness characterized by sadness, loss of interest and loss of appetite thus creating a negative effect on a person's feelings, thought process and the way of handling daily activities. A recent statistical analysis from the world health organization, 2015 has reported that globally around 350 million people are affected by depression. Bipolar disorder is one of the serious mental conditions in which a person suffers severe mood swings -concurrent elated mood (mania) and depressed mood (depression) that may be accompanied by psychotic symptoms with inter current periods either with or without the presence of affective symptoms. Bipolar disorder is the $6^{\text {th }}$ leading cause of disability worldwide with a lifetime prevalence of about $3 \%$ in the general population ${ }^{[1]}$.

\footnotetext{
${ }^{1}$ Department of Psychiatry, PSG Institute of Medical Science \& Research, Coimbatore, Tamilnadu, India

${ }^{2}$ Associate Professor, Department of Psychiatry, PSG Institute of Medical Sciences and Research, Coimbatore,

Tamilnadu, India

*Responding Author

(C) 2016 G Mohankumar, P Palaniappan; licensee IJIP. This is an Open Access Research distributed under the terms of the Creative Commons Attribution License (http://creativecommons.org/licenses/by/2.0), which permits unrestricted use, distribution, and reproduction in any Medium, provided the original work is properly cited.
} 


\section{Prevalence and Pattern of Sleep Disturbances among Mood Disorder Inpatients}

Sleep disturbances which include a wide spectrum of problems from insomnia-sleep onset insomnia, sleep maintenance insomnia, terminal insomnia to parasomnia-nightmares, sleep walking, sleep talking, sleep apnoea affect the ability of a person to sleep well on a regular basis.

Sleep disturbances related to bipolar disorder run the gamut from sleeping too much to not sleeping at all. One of the reasons why sleep impairment is of great concern in bipolar affective disorder is because it acts as a prodrome for the onset of a bipolar episode ${ }^{[2]}$. Therefore, in order to prevent the risk of relapse or hospitalization of bipolar patients, resetting their biological clock which regulates the sleep wake cycle can be useful ${ }^{[3]}$.There exists a definite connection between sleep disruptions and major depression which when not looked at may even result in death by suicide.

Studies focusing on the coexistence of different types of sleep disturbances during a single episode of mood disorder are very few. The present study is aimed at examining the prevalence and coexistence of insomnia, hypersomnia and various other irregular sleep patterns during the acute phase of illness, trying to decipher whether sleep disturbances differ across these disorders.

\section{REVIEW OF LITERATURE}

Insomnia has been found to be associated with psychiatric illnesses in about two-third of patients and more than half of them had a mood disorder ${ }^{[4]}$.Bipolar affective disorder patients exhibit various patterns of sleep disturbances either before the occurrence of a bipolar episode or during the course of illness and sometimes in both the conditions. Sleep disruptions are considered to be the most common prodrome of mania ${ }^{[5,6]}$.About $69-99 \%$ of mania patients report reduced need for sleep ${ }^{[7]}$.Sleep pattern in individuals affected by bipolar depression shows a great variation. About $38-78 \%$ of bipolar depression patients exhibit hypersomnia ${ }^{[8]}$.There is strong association between poor sleep and low work performance in bipolar subjects ${ }^{[11]}$. Although there exists an ample amount of great advances in the therapeutic modalities for bipolar disorder, it still remains as a severe and chronic psychiatric illness with a lifetime prevalence of $1 \%{ }^{[16]}$.Hence further studies on the role of sleep disturbances in bipolar episode relapse is required since impairment of sleep exhibits a strong connection with the recurrence of bipolar episodes.

Descriptive data regarding sleep in case of depression is the best documented in the field. Insomnia may occur in $60-80 \%$ of depressive patients ${ }^{[17]}$. Sleep disturbances in major depressive disorder is characterized by sleep onset insomnia which exhibits increased sleep latency ,sleep maintenance insomnia characterized by disruptions in the continuity of sleep, terminal insomnia characterized by early wakefulness and diminished slow wave sleep. The pattern of sleep in depression patients revealed that early waking (terminal insomnia) is more marked in patients with endogenous depression than in those with reactive depression ${ }^{[19]}$.Thus insomnia has been regarded as one of the symptoms of depression. On the other hand, depression itself is a risk 


\section{Prevalence and Pattern of Sleep Disturbances among Mood Disorder Inpatients}

factor for insomnia ${ }^{[20]}$. Therefore, despite recovery from other depressive symptoms, the depressive individuals have a greater chance of ending up their lives by committing suicide due to the sleep impairment encountered by them ${ }^{[27]}$.The high rates, pervading presence and deleterious impact of sleep disturbances in depression has created the necessity of more studies in relation to it.

\section{Aim of the study}

- To study the prevalence and pattern of sleep disturbance among mood disorder patients admitted in the psychiatry ward at PSG IMS \& R.

\section{Objectives of the study}

1. To estimate the prevalence of insomnia in mood disorder patients.

2. To estimate the pattern of insomnia in the subtypes of mood disorder (Unipolar depression, Bipolar depression, manic episodes, mixed episodes)

3. To correlate different patterns of insomnia with socioeconomic profile.

\section{MATERIALS AND METHODS}

\section{Study Design}

Cross sectional study

\section{Study Population}

Patients admitted in the psychiatric ward with a diagnosis of mood disorder [Bipolar disorder current episode Mania, Bipolar disorder current episode- Mixed, Major depressive episode (unipolar depression), recurrent depressive disorder]diagnosed by the consultant psychiatrist at the Psychiatry OPD, PSG IMS \& R, using Diagnostic and Statistical Manual-IV TR.

\section{Inclusion Criteria}

1. Patients admitted with a diagnosis of mood disorder (using DSM IV TR) in psychiatric ward[Bipolar disorder current episode Mania, Bipolar disorder current episode- Mixed, Major depressive episode (unipolar depression), recurrent depressive disorder]

2. Patient/Informant willing for written informed consent for this study.

\section{Exclusion Criteria}

1. Patient/Informant not willing for written informed consent.

2. Comorbid substance use disorder(except nicotine dependence).

3. Comorbid psychiatric illness.

4. Comorbid medical illness which can contribute to sleep disturbance(Obstructive sleep apnoea, Cancer) 


\section{METHODOLOGY}

Admitted Patients $(\mathrm{n}=60)$ diagnosed by the psychiatrists to have mood disorder [Bipolar disorder current episode Mania, Bipolar disorder current episode- Mixed, Major depressive episode (unipolar depression), recurrent depressive disorder]were screened for inclusion and exclusion criteria. With Prior informed consent, those participants who fulfill inclusion and exclusion criteria were recruited by consecutive sampling. The diagnosis of mood disorder- major depressive disorder, bipolar disorder with the current episode of mania or depression was established by SCID IV interview (Structured Clinical Interview for DSM-IV TR). A semi structured proforma was used to collect details on socio-demographic data, medical history, past psychiatric history \& comorbid psychiatric illness. Current illness records were reviewed to get details on duration of illness, current episode, Number of episodes which required hospitalization, number of episodes which had suicidal attempts \& rapid cycling course. Data regarding sleep was collected from the patient using translated (Tamil) self-administered scale, Pittsburgh Sleep Quality Index (PSQI) ${ }^{[30]}$, which collects information on sleep latency, sleep efficiency, day time sleepiness, Need for medications for sleep \& quality of sleep. PSQI had been validated in multiple cultures, languages and multiple psychiatric disorders, especially depression and bipolar disorder. ${ }^{[30]}$ The study was conducted with prior approval of Institutional hospital ethics committee as per Indian Council of Medical research Guidelines for human studies.

\section{Statistical Analysis}

Data so collected were statistically evaluated using SPSS (Statistical Package for Social Science) software version 19. Socio demographic data were compared among the groups (Unipolar Depression, Bipolar depression \& Bipolar Mania) using chi square test for categorical variables \& ANOVA for continuous variables. The scores obtained by PSQI (pattern of sleep abnormalities) were compared among the groups using ANOVA with post Hoc Tukey test for within group differences. The difference among groups were tested for statistical significance with $\mathrm{P}<0.05$.

\section{RESULTS}

Recruited samples were totally 60 (Unipolar depression - 26, Bipolar Mania -16, Bipolar depression being 14). Comparison of socio-demographic data (Table 1) didn't show any statistical difference among 3 groups in age, gender, occupation, marital status, employment, socio economic status or residence, meaning that the population was not different among the groups in socio demographic data. On exploration of Clinical profile among 3 groups (Table 2), patients who belonged to Bipolar depression had earlier age of onset $(25.36 \pm 10.95, \mathrm{f}=4.8$, $\mathrm{p}=0.02)$, when compared to subjects with bipolar mania (28.79 \pm 9.57$)$ \& Unipolar depression (35.88 \pm 13.76$)$. Otherwise, there was no difference in the severity of illness as shown by Number of episodes, Number of episodes which required hospitalization, number of episodes which had suicidal attempts and number of episodes which had psychotic symptoms. 


\section{Prevalence and Pattern of Sleep Disturbances among Mood Disorder Inpatients}

Regarding sleep disturbances among the groups, as measured by PSQI, all groups had almost equal disturbances in duration of sleep, sleep disturbance, sleep latency, day's dysfunction due to sleepiness, sleep efficiency and overall sleep quality. As per PSQI scoring as Buysee DJ et al $1989^{[30]}$, sleep quality is considered poor if PSQI score is $>5$. In our study, it showed that all

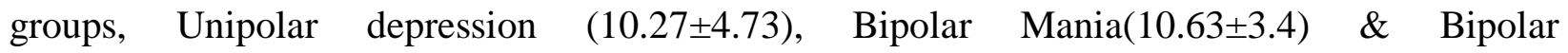
depression(10.14 \pm 4.14$)$ groups had poor quality of sleep during the acute phase of the illness during hospital stay in spite of being on medications(Mood stabilizers- 80\%, Antipsychotics 95\%, Benzodiazepines -60\%, Antidepressants - 20\%). There was no statistical difference among the groups in percentage of use of benzodiazepines across the groups $(p=0.93)$ (data not shown). There was no statistical difference in the overall score of PSQI ( $\mathrm{F}=0.06, \mathrm{P}=0.93$ ), meaning that all three groups were equally affected by sleep disturbance.

\section{DISCUSSION}

In our study, it was observed that irrespective of diagnostic groups, all patients with mood disorder (Unipolar depression, Bipolar Mania, \& Bipolar depression) show significant sleep disturbances as measured by PSQI during the acute phase of illness during the hospital stay in spite of being on medications.

Bipolar disorder interferes with the body's normal circadian rhythm and alters it leading to sleep disruptions ${ }^{[7] .}$ Sleep disturbance in bipolar disorder has become an important marker clinically in predicting the relapse of a bipolar episode ${ }^{[6]}$ Early identification of pattern of sleep disturbances would help us prevent the worsening of sleep disorder ${ }^{[3,10]}$.It plays a vital role in controlling the severity of the underlying mood disorder and it also reduces the rate of relapse ${ }^{[2-4,9-11]}$. Interventions are made to counteract the negative impact created by the sleep impairment on the overall course of the disease, treatment outcomes and enhance the quality of life further ${ }^{\text {[12-14] }}$. Euthymic bipolar patients exhibit clinically significant sleep disturbances, decrease in sleep efficiency, reduction in performing daytime activities and above all anxiety and stress about not sleeping well ${ }^{[12]}$. Sleep impairment in bipolar disorder results in decrease in the energy level which in turn leads to lessened likelihood of engaging in healthy behaviors such as socializing with fellow people and taking care of one's own self ${ }^{[13]}$. This has created the need for increase in the use of sleep medications in bipolar disorder ${ }^{[14]}$. At the same time, bipolar depression is also linked to severe insomnia ${ }^{[7]}$.Altogether bipolar depression exerts a lifetime prevalence of $8.2 \%$ for insomnia and a lifetime prevalence of $8 \%$ for alternating hypersomnia and insomnia ${ }^{[9]}$. This implies that insomnia is highly prevalent in bipolar subjects ${ }^{[10]}$.

Among Unipolar depression, most common of sleep disturbance is sleep maintenance insomnia with a prevalence of $24.4 \%$, sleep onset and terminal insomnia are also highly prevalent in depression with a prevalence rate of $23 \%{ }^{[18]}$, which were not qualitatively examined in our study. In addition to insomnia, hypersomnia may also prevail in depression ${ }^{[22]}$ almost $30 \%$ prevalent among the depressed individuals ${ }^{[23]}$, but our study didn't find such association during 


\section{Prevalence and Pattern of Sleep Disturbances among Mood Disorder Inpatients}

inpatient stay. Excessive daytime sleepiness worsens the depressive symptoms ${ }^{[24]}$, which has been substantiated in our study. Nightmares are the most common parasomnia occurring in depression and is characterized by sudden arousal from deep sleep during which the individual exhibits anxiety, phobia, poor self image ${ }^{[25,28]}$, but our study didn't find such association either in unipolar or bipolar phase of depression. Sleep disturbances is strongly associated with an increased risk for suicidal ideation. ${ }^{[27]}$

Our study results need to be taken with caution because of following limitations. Our study was hospital based inpatient study which could not be generalized to outpatient mood disorders. Our sample size was small and thus needs a larger sample to find further associations. Our study subjects were on medications while the cross sectional assessment was made, and thus it may not reflect the actual sleep disturbances, but it will be unethical to remove the medications for doing the study.

\section{CONCLUSION}

In spite of above limitations, our study result emphasize that equally poor sleep quality exists among all in-patients ${ }^{[29]}$ who suffer from mood disorder irrespective of the diagnostic status \& thus treating the sleep disturbances in these subjects will be of paramount importance. Future studies with larger sample size are required to generalize the findings across all mood disorders.

\section{Acknowledgments}

The author appreciates all those who participated in the study and helped to facilitate the research process.

\section{Conflict of Interests}

The author declared no conflict of interests.

\section{REFERENCES}

1. Boland EM, Alloy LB, "Sleep disturbance and cognitive deficits in bipolar disorder: toward an integrated examination of disorder maintenance and functional impairment”. Clinical Psychology Rev 2013; Feb33 (1): 33-44.

2. Talbot LS, Stone S, Gvuber J, Hairston IS, Eidelman P, Harvey AG."A test of the bidirectional association between sleep and mood in bipolar disorder and insomnia”. Journal of Abnormal Psychology 2012 Feb;121(1):39-50.

3. Kaplan KA, Harvey AG."Behavioural treatment of insomnia in bipolar disorder”. American Journal of Psychiatry 2013 July;170(7):716-20.

4. Tan Tl,Kales JD, Kales A et al.”Biopsycho behavioral correlates of insomnia -Diagnosis based on DSM III”. American Journal of Psychiatry 1994;141:357-62.

5. Jackson A, Cavanagh J, Scott J. “A systematic review of manic and depressive prodromes”. J Affect Disord. 2003;74(3):209-217. 
6. Sierra P, Livianos L, Arques S, Castelló J, Rojo L. "Prodromal symptoms to relapse in bipolar disorder”. Aust N Z J Psychiatry. 2007;41(5):385-391.

7. Robillard R, Naismith SL, Hickie IB. "Recent advances in sleep-wake cycle and biological rhythms in bipolar disorder”. Curr Psychiatry Rep. 2013;15(10):1-10.

8. Kaplan K, McGlinchey E, Soehner A, et al.” Hypersomnia subtypes, sleep and relapse in bipolar disorder”. Psychol Med. 2015;45(08):1751-1763.

9. Breslau N, Roth T, Rosenthal L, Andreski P. "Sleep disturbance and psychiatric disorders: a longitudinal epidemiological study of young adults”. Biol Psychiatry 1996; 39:411-418.

10. Morin CM, Bélanger L, LeBlanc M, Ivers H, Savard J, et al. "The natural history of insomnia: a population-based 3-year longitudinal study”. Arch Intern Med. 2009; 169:447-453.

11. Harvey AG, Schmidt DA, Scarna A, Semler CN, Goodwin GM. "Sleep related functioning in euthymic patients with bipolar disorder, patients with insomnia, and subjects without sleep problems”. Am J Psychiatry 2005;162(1):50-57.

12. Boland EM, Stange JP, Molz Adams A, et al. "Associations between sleep disturbance, cognitive functioning and work disability in Bipolar Disorder”. Psychiatry Res 2015; 230(2):567-574.

13. Harvey AG, Talbot LS, Gershon A. "Sleep disturbance in bipolar disorder across the lifespan”. Clin Psychol SciPract 2009;16(2):256-277.

14. Sylvia LG, Dupuy JM, Ostacher MJ, et al. “Sleep disturbance in euthymic bipolar patients”. J Psychopharmacol. 2012;26(8):1108-1112.

15. Lai Y-C, Huang M-C, Chen H-C, et al. "Familiarity and clinical outcomes of sleep disturbances in major depressive and bipolar disorders”. J PsychosomRes. 2014; 76(1):61-67.

16. Merikangas KR, Jin R, He JP, Kessler RC, Lee S, et al. "Prevalence and correlates of bipolar spectrum disorder in the world mental health survey initiative”. Arch Gen Psychiatry. 2011; 68:241-251

17. Winkour A, Gary KA, Rodner SMRae-Red C, Fernando AT, Szuba MP.”Depression, sleep physiology, and antidepressant drugs.”Depress anxiety.2001;14:19-28.

18. Guruje O, Kola L, Ademola A, Olley BO.”Profile, comorbidity and impact of insomnia in the Ibadan study of ageing.Int J GeriatrPsychiatry.2009;24:686-693.

19. Ijaz Haider. “Patterns of insomnia in depressive illness: A Subjective evaluation”. British journal of Psychiatry. 1986; 34: 279-84.

20. Perlis ML,Giles DE, Buysse DJ, Tu X, Kupfer DJ.”Self-repotes sleep disturbance as a prodromal symptom in recurrent depression”. J Affect Disord.1997;42:209-12.

21. Santos Maoraes WA, Burke PR, Coutinho PL et al.”Sedative antidepressants and insomnia.”Rev Bras Psiquiatr.2011;33:91-95.

22. Posternak MA, Zimmerman M.”Symptoms of atypical depression.”Psychiatry Res. 2001;104:175-181. 
23. Kaplan KA,Harvey AG.”Hypersomnia across mood disorders: a review and synthesis.”Sleep Med Rev.2009;13;275-285.

24. Adrien J, Madhuit C, Martin P.”Antidepressant like effects of paradoxical sleep deprivation I the learned helplessness paradigm.”J Sleep Res.1992;1:S2.

25. Beauchemin KM, Hays P.”Dreaming way depression: the role of REM sleep and dreaming in affective disorders. J AffectDisorder.1996;41:125-133.

26. Ohayan MM, Morselli PL, Guilleminault C.”Prevalence of nightmares and their relationship to psychopathology and daytime functioning in insomnia subjects”.Sleep.1997;20:340348.

27. McCall WV, Batson N, Webster M,et al.”Nightmares and dysfunctional beliefs about sleep mediate the effect of insomnia symptoms on suicidal ideation”. J Clin Sleep Med.2013;9:135-140.

28. Arriaga F, Rosado P, Paiva T. The sleep of dysthymic patients: a comparison with normal controls. Biol Psychiatry. 1990 Mar 15;27(6):649-56.

29. Tsujimoto T1, Yamada N, Shimoda K, Hanada K, Takahashi S.Circadian rhythms in depression. Part II: Circadian rhythms in inpatients with various mental disorders. J Affect Disord. 1990 Mar;18(3):199-210.

30. Buysse DJ, Reynolds CF 3rd, Monk TH, Berman SR, Kupfer DJ. The Pittsburgh Sleep Quality Index: a new instrument for psychiatric practice and research. Psychiatry Res. 1989 May;28(2):193-213.

Table 1: Socio Demographic details of the subjects:

\begin{tabular}{|c|c|c|c|c|c|c|}
\hline S.No & Characteristics & $\begin{array}{l}\text { Unipolar } \\
\text { Depression ( } \\
\mathbf{n = 2 6} \text { ) }\end{array}$ & $\begin{array}{l}\text { Bipolar } \\
\text { Mania ( } \\
n=19)\end{array}$ & $\begin{array}{l}\text { Bipolar } \\
\text { Depression ( } \\
n=14)\end{array}$ & $\begin{array}{l}\mathbf{F} \\
\text { value/ } \chi\end{array}$ & $P$ value \\
\hline 1. & $\begin{array}{l}\text { Age ( Years ) ( Mean } \\
\pm \text { S.D) }\end{array}$ & $\begin{array}{l}41.96 \pm \\
14.56\end{array}$ & $\begin{array}{l}37.79 \pm \\
10.94\end{array}$ & $\begin{array}{l}37.07 \pm \\
10.33\end{array}$ & 0.851 & 0.433 \\
\hline \multirow[t]{3}{*}{2.} & Marital Status & & & & 2.58 & 0.275 \\
\hline & Single & $5(19 \%)$ & $6(32 \%)$ & $6(29 \%)$ & & \\
\hline & Married & $21(81 \%)$ & $13(68 \%)$ & $8(71 \%)$ & & \\
\hline \multirow[t]{3}{*}{3.} & Gender & & & & 1.453 & 0.484 \\
\hline & Male & $13(50 \%)$ & $12(63 \%)$ & $6(43 \%)$ & & \\
\hline & Female & $13(50 \%)$ & 7 ( 37\%) & $8(57 \%)$ & & \\
\hline \multirow[t]{2}{*}{4} & Occupation & & & & 4.98 & 0.289 \\
\hline & Unemployed & $16(62 \%)$ & $8(42 \%)$ & $9(64 \%)$ & & \\
\hline
\end{tabular}

(c) The International Journal of Indian Psychology, ISSN 2348-5396 (e) | ISSN: 2349-3429 (p) | 123 
Prevalence and Pattern of Sleep Disturbances among Mood Disorder Inpatients

\begin{tabular}{|c|c|c|c|c|c|c|}
\hline S.No & Characteristics & $\begin{array}{l}\text { Unipolar } \\
\text { Depression ( } \\
\mathrm{n}=26 \text { ) }\end{array}$ & $\begin{array}{l}\text { Bipolar } \\
\text { Mania ( } \\
\mathrm{n}=19 \text { ) }\end{array}$ & $\begin{array}{l}\text { Bipolar } \\
\text { Depression ( } \\
\mathrm{n}=14 \text { ) }\end{array}$ & $\begin{array}{l}\text { F } \\
\text { value/ } \chi\end{array}$ & $P$ value \\
\hline & Semiskilled & $8(31 \%)$ & $11(58 \%)$ & $4(29 \%)$ & & \\
\hline & Skilled & $2(7 \%)$ & $0(0 \%)$ & $1(7 \%)$ & & \\
\hline \multirow[t]{8}{*}{5} & Education & & & & & \\
\hline & Illiterate & $2(7 \%)$ & $2(11 \%)$ & 0 & 10.18 & 0.683 \\
\hline & Nursery & $1(4 \%)$ & 0 & 0 & & \\
\hline & Primary & $6(23 \%)$ & $3(18 \%)$ & $1(7 \%)$ & & \\
\hline & Secondary & $6(23 \%)$ & $4(20 \%)$ & $6(43 \%)$ & & \\
\hline & Higher & $3(12 \%)$ & $6(31 \%)$ & $2(14 \%)$ & & \\
\hline & Undergraduate & $7(27 \%)$ & $4(20 \%)$ & $5(36 \%)$ & & \\
\hline & Postgraduate & $1(4 \%)$ & 0 & 0 & & \\
\hline \multirow[t]{4}{*}{6} & $\begin{array}{l}\text { Socio Economic } \\
\text { status }\end{array}$ & & & & 1.10 & 0.893 \\
\hline & Lower & $10(39 \%)$ & 7(37\%) & $4(29 \%)$ & & \\
\hline & Middle & $14(53 \%)$ & $11(58 \%)$ & $8(57 \%)$ & & \\
\hline & Upper & $2(8 \%)$ & $1(5 \%)$ & $2(14 \%)$ & & \\
\hline \multirow[t]{3}{*}{7} & Residence & & & & 1.99 & 0.368 \\
\hline & Urban & $9(35 \%)$ & $9(47 \%)$ & $8(57 \%)$ & & \\
\hline & Rural & 17(65\%) & $10(53 \%)$ & $6(43 \%)$ & & \\
\hline
\end{tabular}

Table 2: Clinical profile of subjects:

\begin{tabular}{|l|l|l|l|l|l|l|}
\hline S.No & Characteristics & $\begin{array}{l}\text { Unipolar } \\
\text { Depression ( } \\
\mathbf{n = 2 6 )}\end{array}$ & $\begin{array}{l}\text { Bipolar } \\
\text { Mania ( } \\
\mathbf{n = 1 9 )}\end{array}$ & $\begin{array}{l}\text { Bipolar } \\
\text { Depression ( } \\
\mathbf{n = 1 4 )}\end{array}$ & F & P value \\
\hline 1. & Age of onset & $35.88 \pm 13.76$ & $\begin{array}{l}28.79 \\
\pm 9.57\end{array}$ & $25.36 \pm 10.95$ & 4.8 & 0.02 \\
\hline 2. & Number of episodes & $5.15 \pm 9.34$ & $5.16 \pm 6.47$ & $4.07 \pm 1.6$ & 0.118 & 0.889 \\
\hline
\end{tabular}

(c) The International Journal of Indian Psychology, ISSN 2348-5396 (e)| ISSN: 2349-3429 (p) | 124 
Prevalence and Pattern of Sleep Disturbances among Mood Disorder Inpatients

\begin{tabular}{|l|l|l|l|l|l|l|}
\hline S.No & Characteristics & $\begin{array}{l}\text { Unipolar } \\
\text { Depression ( } \\
\mathbf{n = 2 6 )}\end{array}$ & $\begin{array}{l}\text { Bipolar } \\
\text { Mania ( } \\
\mathbf{n = 1 9 )}\end{array}$ & $\begin{array}{l}\text { Bipolar } \\
\text { Depression ( } \\
\mathbf{n = 1 4 )}\end{array}$ & $\mathbf{F}$ & P value \\
\hline 3. & $\begin{array}{l}\text { Number of episodes } \\
\text { with psychotic } \\
\text { symptoms }\end{array}$ & $0.58 \pm 0.17$ & $0.21 \pm 0.53$ & $0.43 \pm 0.64$ & 0.919 & 0.405 \\
\hline 4. & $\begin{array}{l}\text { Number of episodes } \\
\text { with suicidal } \\
\text { attempts }\end{array}$ & $1.12 \pm 0.97$ & $0.05 \pm 0.22$ & $0.57 \pm 0.32$ & 0.086 & 0.917 \\
\hline 5 & $\begin{array}{l}\text { Number of episodes } \\
\text { which needed } \\
\text { hospitalization }\end{array}$ & $3.12 \pm 3.6$ & $2.53 \pm 1.77$ & $2.57 \pm 1.45$ & 1.476 & 0.237 \\
\hline
\end{tabular}

Table 3: Comparison of PSQI scores among the groups:

\begin{tabular}{|l|l|l|l|l|l|l|}
\hline S.No & PSQI Components & $\begin{array}{l}\text { Unipolar } \\
\text { Depression ( } \\
\mathbf{n = 2 6 )}\end{array}$ & $\begin{array}{l}\text { Bipolar } \\
\text { Mania ( } \\
\mathbf{n = 1 9 )}\end{array}$ & $\begin{array}{l}\text { Bipolar } \\
\text { Depression ( } \\
\mathbf{n = 1 4 )}\end{array}$ & $\mathbf{F}$ & P value \\
\hline 1. & Duration of Sleep & $1.27 \pm 0.82$ & $1.47 \pm 0.77$ & $1.57 \pm 0.85$ & 0.71 & 0.49 \\
\hline 2. & Sleep Disturbance & $2.12 \pm 1.33$ & $2.26 \pm 1.32$ & $2.07 \pm 1.07$ & 0.11 & 0.89 \\
\hline 3. & Sleep Latency & $1.69 \pm 1.15$ & $2.11 \pm 1.10$ & $1.93 \pm 1.26$ & 0.70 & 0.5 \\
\hline 4. & $\begin{array}{l}\text { Days dysfunction } \\
\text { due to sleepiness }\end{array}$ & $1.12 \pm 0.65$ & $1.37 \pm 1.25$ & $1.29 \pm 1.26$ & 0.25 & 0.77 \\
\hline 5. & Sleep efficiency & $1.54 \pm 1.42$ & $1.21 \pm 0.8$ & $1.14 \pm 0.36$ & 0.95 & 0.39 \\
\hline 6. & $\begin{array}{l}\text { Overall sleep } \\
\text { quality }\end{array}$ & $1.12 \pm 0.65$ & $1.1 \pm 0.65$ & $0.71 \pm 0.26$ & 0.48 & 0.62 \\
\hline 7. & $\begin{array}{l}\text { Need for } \\
\text { medications for } \\
\text { sleep }\end{array}$ & $1.31 \pm 1.05$ & $1.21 \pm 0.85$ & $1.43 \pm 1.08$ & 0.19 & 0.82 \\
\hline 8. & Total & $10.27 \pm 4.73$ & $10.63 \pm 3.4$ & $10.14 \pm 4.14$ & 0.06 & 0.93 \\
\hline
\end{tabular}

How to cite this article: G Mohankumar, P Palaniappan (2016), Prevalence and Pattern of Sleep Disturbances among Mood Disorder Inpatients, International Journal of Indian Psychology, Volume 4, Issue 1, No. 79, ISSN:2348-5396 (e), ISSN:2349-3429 (p), DIP:18.01.092/20160304, ISBN:978-1-365-56745-2

(c) The International Journal of Indian Psychology, ISSN 2348-5396 (e)| ISSN: 2349-3429 (p) | 125 